\title{
Five Regioisomers of Dimethyl Dodecahedrane Derivatives: A Hybrid DFT B3LYP Study
}

\author{
Seol Lee, YongJae Cho, and Kee Hag Lee \\ Department of Chemistry and Nanoscale Sciences and Technology Institute, Wonkwang University, Iksan, \\ Jeonbuk 570-749, Republic of Korea \\ Correspondence should be addressed to Kee Hag Lee; khlee@wku.ac.kr
}

Received 22 February 2017; Revised 3 June 2017; Accepted 3 July 2017; Published 20 September 2017

Academic Editor: Arturo Espinosa Ferao

Copyright (C) 2017 Seol Lee et al. This is an open access article distributed under the Creative Commons Attribution License, which permits unrestricted use, distribution, and reproduction in any medium, provided the original work is properly cited.

The hybrid density functional (B3LYP/6-31G $(\mathrm{d}, \mathrm{p})$ ) method was used to understand why 1,2-dimethyl dodecahedrane has not been reported yet. From the direct dimethyl substitution of the dodecahedrane cage, we could have five $\mathrm{C}_{20} \mathrm{H}_{18}\left(\mathrm{CH}_{3}\right)_{2}$ derivatives which were geometrically optimized without constraints. The results suggest that 1,16-dimethyl dodecahedrane derivative is the most stable, whereas the 1,2-dimethyl derivative is the most unstable; this implies that the distortion due to steric hindrance interactions would be a crucial effect on the relative energies of the dimethyl dodecahedranes. It would be disadvantaged thermodynamically for 1,2-dimethyl derivative that, in the experimental results, was not synthesized yet. The LUMO of each of the derivatives was equivalently delocalized over the void within the cage, implying that dimethyl derivatives are able to encapsulate atoms at the center of the cage. The HOMO was limitedly delocalized on the cage. The characteristics of the HOMO of derivatives show three patterns, implying that each derivative might undergo one of three entirely different sets of characteristic chemical reactions with electrophilic reagents.

Dedicated to Professor Roald Hoffmann on the occasion of his 80th birthday

\section{Introduction}

The geometry of fullerenes obeys the isolated-pentagon rule. However, this rule cannot be satisfied for the smallest fullerene $\mathrm{C}_{20}$, which contains twelve 5-membered rings (MRs) and zero 6-MRs. Therefore, the $\mathrm{C}_{20}$ fullerene would be highly reactive owing to the fusion of strained 5-MRs. Furthermore, this strain could be removed through reactions of $\mathrm{C}_{20}$ that form $\mathrm{sp}^{3}$ bonds. By using density functional theory method, the structures and electronic states of alkyl radicals $\left(\mathrm{R}, \mathrm{C}_{n} \mathrm{H}_{2 n+1}, n=1-4\right)$ added to $\mathrm{C}_{20}$ fullerenes were investigated [1]. Also it was proposed that thiyl radicalpromoted polycyclization to form dodecahedrane would be exergonic [2].

Density functional calculations of the reactions $\mathrm{CX}_{3}$ radical $+\mathrm{C}_{20} \mathrm{H}_{20}(\mathrm{X}=\mathrm{H}, \mathrm{F}, \mathrm{Cl}$, and $\mathrm{Br}$ ) based on two pathways
(H-displacement and $\mathrm{H}$-abstraction from $\mathrm{C}_{20} \mathrm{H}_{20}$ ) showed that $\mathrm{CH}_{3}$ radical prefers $\mathrm{H}$-abstraction from $\mathrm{C}_{20} \mathrm{H}_{20}$ while $\mathrm{F}$ displacement is favorable for the reaction of $\mathrm{CF}_{3}$ radical with the fullerene. Exothermic characters of $\mathrm{H}$-abstraction with the lower potential barrier indicate that the $\mathrm{H}$-abstraction would dominate the reaction $\mathrm{CCl}_{3}{ }^{\circ}+\mathrm{C}_{20} \mathrm{H}_{20}$ while endothermic characters with high potential barrier heights for two reaction pathways of $\mathrm{C}_{20} \mathrm{H}_{20}$ with $\mathrm{CBr}_{3}{ }^{\circ}$ indicate unfavorable thermodynamically and kinetically pathways for these reactions [3].

Using the PBE0/cc-pVDZ quantum chemical method, dipole moments, polarizabilities, the first hyperpolarizabilities for 1,2-diethynyldodecahedrane $\mathrm{C}_{20} \mathrm{H}_{18}(\mathrm{CCH})_{2}$ and diethynylmethanododecahedrane $\mathrm{C}_{20} \mathrm{H}_{18} \mathrm{C}(\mathrm{CCH})_{2}$ including two neighboring ethynyl groups in vacuum and in tetrahydrofuran (THF) were reported [4]. 
A dodecahedrane derivative, namely, the $\mathbf{D}_{\mathbf{3 d}}$ symmetric 1,16-dimethyl derivative, has been synthesized experimentally [5-8]. Since then, the synthesis of methyl-substituted dodecahedrane was also confirmed by X-ray analysis. Moreover, Pólya's theorem was applied to the enumeration of substituted dodecahedrane isomers [9]. The total synthesis of dodecahedrane was confirmed by the single-peak nature of the ${ }^{1} \mathrm{H}$ and ${ }^{13} \mathrm{C}$ NMR spectra [10], as well as the X-ray spectra $[11,12]$. Methyl dodecahedrane, 1,4-dimethyl $\left(\mathbf{C}_{\mathrm{s}}\right)$, 1,6-dimethyl $\left(\mathbf{C}_{2 \mathbf{v}}\right), 1,16$-dimethyl $\left(\mathbf{D}_{3 \mathbf{d}}\right)$ dodecahedranes, and trimethyl dodecahedrane have subsequently been reported [13-15]. However, at present no 1,2-dimethyl $\left(\mathbf{C}_{2 \mathbf{v}}\right)$ and 1,7dimethyl $\left(\mathbf{C}_{2}\right)$ dodecahedranes have been reported, yet.

The structures of dodecahedrane and its derivatives were studied at the level of molecular mechanics calculations $[16,17]$, INDO calculations [18], and hybrid density functional B3LYP calculations [19]. Recently the relative energies, electronic properties, and atomic structures of disubstituted $\mathrm{C}_{20} \mathrm{H}_{18} \mathrm{X}_{2}$ regioisomers $(\mathrm{X}=\mathrm{F}, \mathrm{Cl}, \mathrm{Br}$, or $\mathrm{OH}$ ) at the level of B3LYP/6-31G(d,p) have been determined [20]. Here the predominant electronic configurations of the regioisomers with all substituents $\mathrm{X}$ which are higher electron negativity than carbon are not so different, but the HOMO and LUMO maps for five regioisomers are not similar, implying that different exohedral complexes may undergo a distinct set of characteristic chemical reactions.

However, to the best of our knowledge, no the first principle calculations of the full optimization of the five dimethyl dodecahedranes, $\mathrm{C}_{20} \mathrm{H}_{18}\left(\mathrm{CH}_{3}\right)_{2}$ derivatives using B3LYP/6-31G $(\mathrm{d}, \mathrm{p})$, have been reported. Such calculations would be required in order to understand, in the point of energetics, why only three derivatives have been synthesized. Accordingly, in this study we determine the relative energies, electronic properties, and atomic structures of five derivatives with the same spin state, following the methods of Hwang et al. 2012 [20]. Also it is interesting to see the effect of the methyl substituents on the frontier orbitals, because carbon atoms have the same electronegativity in the substituents and the cage.

\section{Calculations}

In this study, hybrid density functional theory (DFT) with Becke's three-parameter hybrid method and the Lee-YangParr exchange-correlation functional theory (B3LYP) [21-28] were used to optimize the geometries of the $\mathrm{C}_{20} \mathrm{H}_{20}$ and five dimethyl derivatives $\mathrm{C}_{20} \mathrm{H}_{18}\left(\mathrm{CH}_{3}\right)_{2}$, as shown in Figure 1 . Furthermore, the electron basis set 6-31G(d,p) was used [25]. We fully optimized the geometries of all the $\mathrm{C}_{20} \mathrm{H}_{18}\left(\mathrm{CH}_{3}\right)_{2}$ derivatives using the Gaussian 2003 B.04 and Gaussian 2009 D01 package suites $[26,27]$. We obtain highly accurate geometries, by using the convergence criterion with tight optimization and an ultrafine pruned $(99,590)$ grid. Here, we analyzed the relative energies as well as the HOMO and LUMO orbitals of the derivatives [20,28].

To attest the veracity of the B3LYP/6-31G(d,p) relative energy values, as shown in Supplementary Material (see Supplementary Material available online at https://doi.org/ $10.1155 / 2017 / 5494038$ ), we calculated single-point energies at
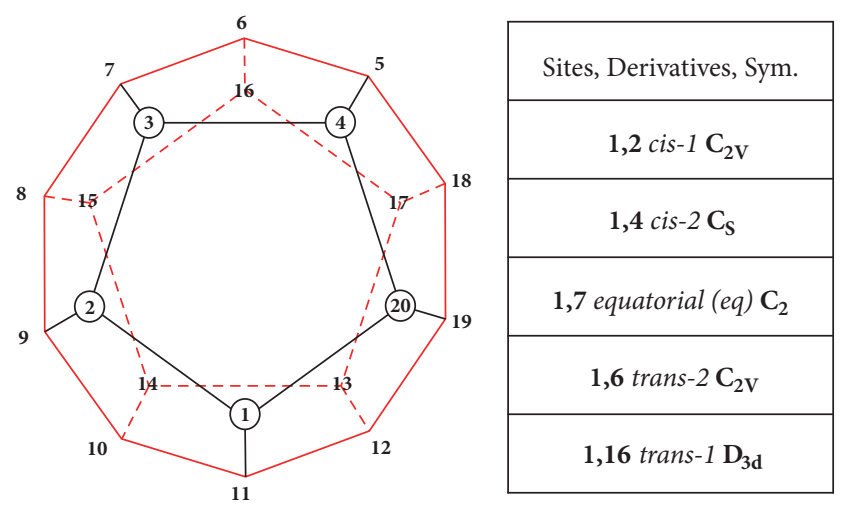

(a)

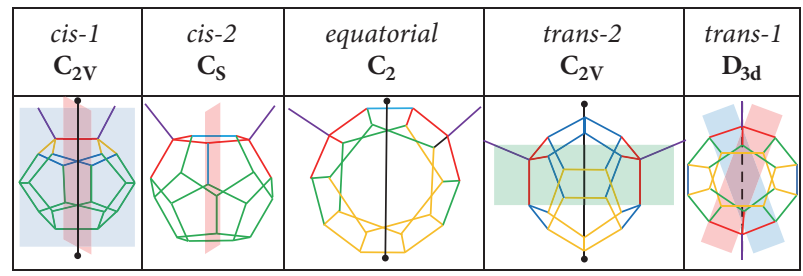

(b)

Figure 1: (a) The dodecahedrane and its numbering system (hydrogen atoms deleted for clarity). (b) The dimethyl substituted dodecahedrane derivatives $\mathrm{C}_{20} \mathrm{H}_{18}\left(\mathrm{CH}_{3}\right)_{2}$.

the levels of M06-2X [29], PBE [30], B98 [31], B97D3 [32, 33], B3LYPD3 [21, 22, 33], PBED3 [30, 33], and M06-2XD3 $[29,33]$ with $6-31 G(d, p)$ basis set on the optimized geometries and using the Zero Point Energy-Correction (ZPEC) already obtained at the B3LYP/6-31G(d) level, using Gaussian 2009 D01 package suites [27]. Here D3 represents the dispersioncorrected functional with the D3 version of Grimme's dispersion with Becke-Johnson damping [33]. Also using the postHF MP2 [34]/def2-TZVPP [35]//B3LYP/6-31G(d) level, we computed the energies as single-point calculations with the ZPEC already obtained at the B3LYP/6-31G(d) level.

\section{Results and Discussion}

By performing calculations for the full optimization of the atomic structures of the five $\mathrm{C}_{20} \mathrm{H}_{18}\left(\mathrm{CH}_{3}\right)_{2}$ derivatives using B3LYP/6-31G $(\mathrm{d}, \mathrm{p})$ without any constraints, we determined the relative energies of the derivatives in Table 1 with the symmetries as shown in Figure 1.

The geometrical structures and the frontier orbitals (HOMOs and LUMOs) of the five $\mathrm{C}_{20} \mathrm{H}_{18}\left(\mathrm{CH}_{3}\right)_{2}$ derivatives are shown in Figure 2. The calculated $\mathrm{C}-\mathrm{C}$ bond length in the cage of neutral $\mathrm{C}_{20} \mathrm{H}_{20}$ with $I_{h}$ symmetry is $1.556 \AA$, which is in the range of the experimental result (i.e., $1.555 \pm 0.001 \AA$ ) [36].

In the five dimethyl derivatives whose geometries were fully optimized, the relative Zero Point Energy-Correction (ZPEC) energies of dimethyl dodecahedranes are arranged in the following order: 1,16-dimethyl derivative (trans-1, $\mathbf{D}_{\mathbf{3 d}}$ ) $\approx 1$,7-dimethyl derivative (equatorial, $\mathrm{C}_{2}$ ) $\approx 1$ 1,6-dimethyl derivative (trans-2, $\mathbf{C}_{2 \mathbf{v}}$ ) $\approx 1$,4-dimethyl derivative (cis-2, $\mathbf{C}_{\mathbf{s}}$ ) 
TABLE 1: The relative energies (rel. E), relative ZPEC energies (rel. ZPEC), relative enthalpy (rel. $\Delta H^{0}$ ), and relative Gibbs free energies (rel. $\Delta G^{0}$ ) in units of $\mathrm{meV}$ and distance (d, $\AA$ ) between the two methyls of the five $\mathrm{C}_{20} \mathrm{H}_{18}\left(\mathrm{CH}_{3}\right)_{2}$ derivatives using B3LYP/6-31G(d, p) calculations ${ }^{\mathrm{a}}$.

\begin{tabular}{lccccc}
\hline Derivative & Rel. $E$ & Rel. ZPEC & $\Delta H^{0}$ & $\Delta G^{0}$ & $\mathbf{d}$ \\
\hline $\mathbf{1 , 2}$-cis-1 & 112.7 & 121.6 & 3 & 9 & 2.88 \\
$\mathbf{1 , 4}$-cis-2 & 2.9 & 2.5 & -3 & -5 & 4.32 \\
$\mathbf{1 , 7}$-eq & 0.8 & 0.4 & -2 & -2 & 6.11 \\
$\mathbf{1 , 6}$-trans-2 & 1.9 & 0.2 & -4 & -7 & 6.99 \\
$\mathbf{1 , 1 6}$-trans-1 & 0.0 & 0.0 & 0 & 0 & 7.48 \\
\hline
\end{tabular}

${ }^{\mathrm{a}}$ The relative value of each derivative is the energy minus the energy of trans1 isomer.

$<1,2$-dimethyl derivative (cis-1, $\mathbf{C}_{2 \mathrm{v}}$ ). The distance between dimethyl groups in the 1,16-dimethyl derivative with the lowest energy is the longest among these. In 1,2-dimethyl derivative, the two substituents are located on the surface of the $\mathrm{C}_{20} \mathrm{H}_{20}$ fullerene within a distance that is shorter than the van der Waals distance (i.e., $3.4 \AA$ ).

The increasing order of relative ZPEC energies in them is the same to the decreasing order of the distance between the two methyl groups of derivatives. As shown in Figure 3 and Supplementary Materials, the veracity of the B3LYP/6$31 \mathrm{G}(\mathrm{d}, \mathrm{p})$ relative energy values is attested at the levels of M062X, PBE, B98, B97D3, B3LYPD3, PBED3, and M06-2XD3, and MP2 in the point of view that the relative energy of cis-1 is about $10 \mathrm{~kJ} / \mathrm{mol}$ higher than the others. The difference of relative energies of four isomers except cis-1 is less than $0.7 \mathrm{~kJ} / \mathrm{mol}$ in the levels of DFT but within $2 \mathrm{~kJ} / \mathrm{mol}$ in the MP2 method.

Our result suggests that both the strength of the cage distortion and the van der Waals force between the pair of methyl groups of derivatives are important factors that affect the position of exohedral dimethyl substitution on the dodecahedrane cage. And it could be suggested that in 1,2dimethyl derivative, steric impedance brought on by the nearby two methyl groups is very crucial. It is interesting to compare the results above with the case of $\mathrm{C}_{20} \mathrm{H}_{18} \mathrm{X}_{2}(\mathrm{X}=\mathrm{F}$, $\mathrm{Cl}, \mathrm{Br}, \mathrm{OH})$. In this case, except for the dihydroxy derivative, 1,2-disubstituted derivatives have the highest energy whereas 1,16-derivatives have the lowest energy; however, in the dihydroxy derivatives, the increasing order is reversed [20, 37].

Here our calculations concerning the dimethyl dodecahedrane derivatives could explain the fact why three dimethyl dodecahedrane derivatives were reported in X-ray and NMR experiments $[7,15]$, but the 1,2-dimethyl dodecahedrane derivative has not been synthesized yet. And it could be suggested that the more stable derivative in the viewpoint of energetics could be synthesized easier than others.

In the following substitution reaction, the thermal reaction energies are endothermic:

$$
\mathrm{C}_{20} \mathrm{H}_{20}+2 \mathrm{CH}_{3} \longrightarrow \mathrm{C}_{20} \mathrm{H}_{18}\left(\mathrm{CH}_{3}\right)_{2}+2 \mathrm{H}
$$

where $2.48,2.86,2.56,3.78$, and $5.79 \mathrm{eV}$ of the thermal reaction energies at $298.15 \mathrm{~K}$ and $1 \mathrm{~atm}$ are absorbed for 1,16-dimethyl derivative (trans-1, $\mathbf{D}_{3 \mathbf{d}}$ ), 1,7-dimethyl derivative (equatorial, $\mathbf{C}_{2}$ ), 1,6-dimethyl derivative (trans-2, $\mathbf{C}_{2 \mathbf{v}}$ ), 1,4dimethyl derivative (cis-2, $\mathbf{C}_{\mathbf{s}}$ ), and 1,2-dimethyl derivative (cis$1, C_{2 \mathrm{v}}$ ), respectively. The Gibbs free energies are 10.285, 10.278, $10.283,10.280$, and $10.294 \mathrm{eV}$ for 1,16-dimethyl derivative (trans-1, $\mathbf{D}_{3 \mathrm{~d}}$ ), C 1,6-dimethyl derivative (trans-2, $\mathbf{C}_{2 \mathrm{v}}$ ), 1,7dimethyl derivative (equatorial, $\mathbf{C}_{2}$ ), 1,4-dimethyl derivative (cis-2, $\mathbf{C}_{\mathbf{s}}$ ), and 1,2-dimethyl derivative (cis-1, $\mathbf{C}_{2 \mathbf{v}}$ ), respectively.

Even though the very small variation of Gibbs free energy is not sufficient to decide which structure should be totally experimentally disfavored, it could suggest that, in the point of thermodynamics, a synthesis of cis-1 isomer might be a little difficult compared to the others. In the experimental results, dodecahedrane, methyl, and dimethyl derivatives are synthesized [12], but cis-1 and equatorial isomers are not synthesized yet.

Figure 2 shows the HOMOs and LUMOs for the directed dimethyl derivatives of the dodecahedrane cage. When we calculate the energy gaps from the HOMO/LUMO energy levels of the derivatives, $\mathrm{C}_{20} \mathrm{H}_{20}$ and $\mathrm{C}_{20} \mathrm{H}_{18}\left(\mathrm{CH}_{3}\right)_{2}$ have slightly different energy gaps. Here the HOMOs of the $\mathrm{C}_{20} \mathrm{H}_{18}\left(\mathrm{CH}_{3}\right)_{2}$ derivatives with the same number of symmetry elements are very similar, but the HOMOs of derivatives with the different number of symmetry elements are different, despite the fact that the LUMOs among different geometric structures are identical. This suggests that each derivative undergoes one of three distinct sets of characteristic chemical reactions only for the HOMO. It is interesting to see that they are different to the case of disubstituted $\mathrm{C}_{20} \mathrm{H}_{18} \mathrm{X}_{2}$ regioisomers $(\mathrm{X}=\mathrm{F}, \mathrm{Cl}, \mathrm{Br}$, or $\mathrm{OH})$ which have five distinct set of reactions for both the HOMO and the LUMO [20].

Figure 2 shows the effect of the disubstituents on the frontier orbitals of $\mathrm{C}_{20} \mathrm{H}_{20}$. The HOMO and LUMO energies of five $\mathrm{C}_{20} \mathrm{H}_{18}\left(\mathrm{CH}_{3}\right)_{2}$ derivatives are higher than the HOMO and LUMO levels of $\mathrm{C}_{20} \mathrm{H}_{20}$ (HOMO: $-7.09 \mathrm{eV}$; LUMO: $0.90 \mathrm{eV})$. Also the band gaps of dimethyl substituted derivatives are wider than the gaps of $\mathrm{C}_{20} \mathrm{H}_{20}$ and $\mathrm{C}_{20}$ (HOMO: $-5.03 \mathrm{eV}$; LUMO: $-3.10 \mathrm{eV}$ ). Moreover, the LUMO energies are positive and higher than that of $\mathrm{C}_{20} \mathrm{H}_{20}$, which implies that these could function less efficiently as electron acceptors than $\mathrm{C}_{20} \mathrm{H}_{20}$.

\section{Conclusion}

We obtained the fully optimized geometries of the $\mathrm{C}_{20} \mathrm{H}_{18}\left(\mathrm{CH}_{3}\right)_{2}$ derivatives (the smallest fullerene disubstituents) without any constraints using the hybrid B3LYP/6$31 \mathrm{G}(\mathrm{d}, \mathrm{p})$ density functional method. We observed that the relative energy of the $\mathrm{C}_{20} \mathrm{H}_{20}$ disubstituted derivatives is mostly dependent on the distance between the pair of two methyl groups. It is interesting to note that the 1,2-dimethyl derivatives is less stable than the 1,16-dimethyl derivative. This implies that, in the $\mathrm{C}_{20} \mathrm{H}_{18}\left(\mathrm{CH}_{3}\right)_{2}$ derivatives, the effect of distortion due to the steric hindrance interactions on the relative energy would be crucial. Therefore, our calculations in the point of thermodynamic view could support the experimental results, wherein three dimethyl dodecahedrane derivatives except the 1,2-dimethyl dodecahedrane derivative 


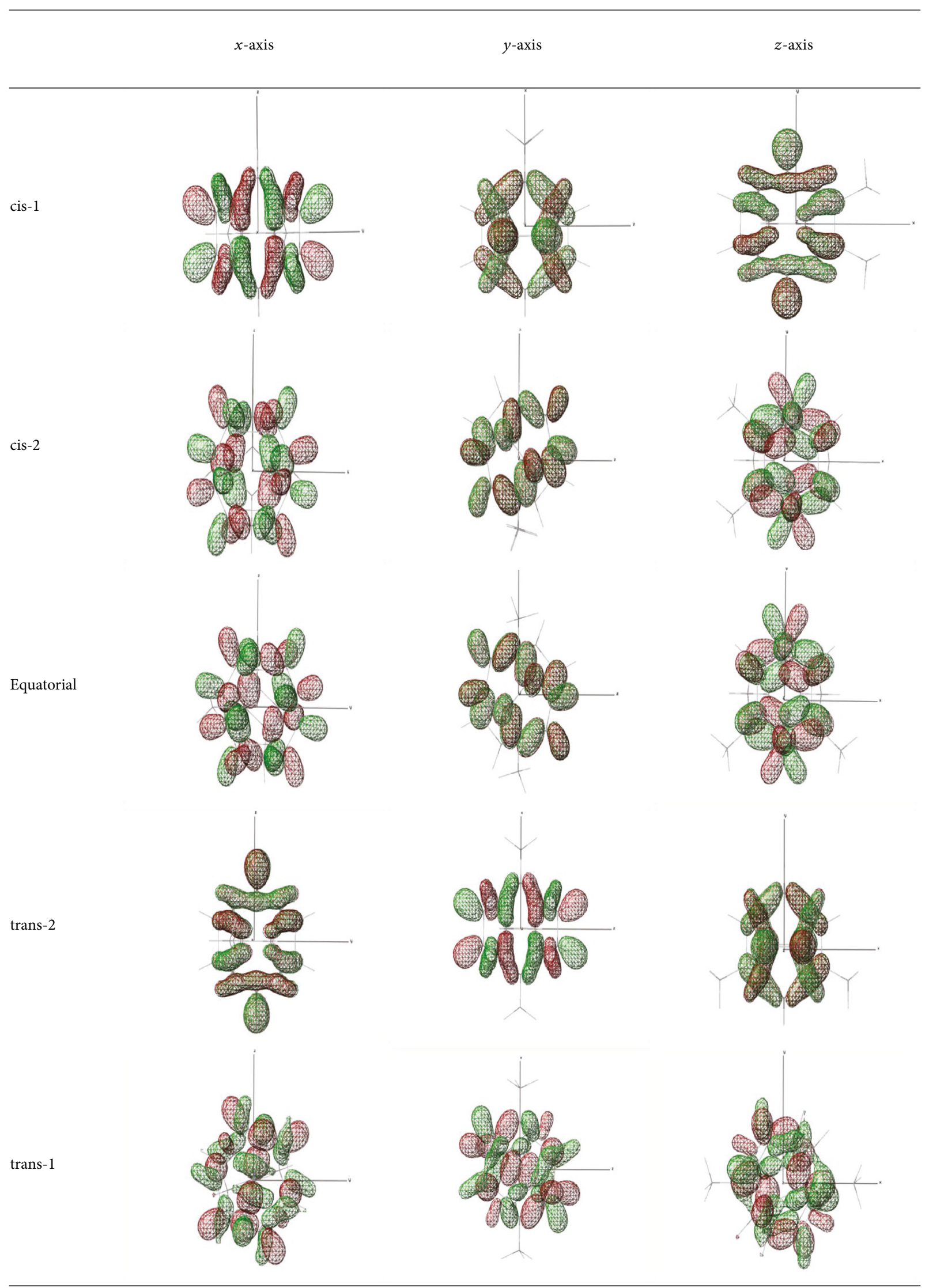

(a)

Figure 2: Continued. 


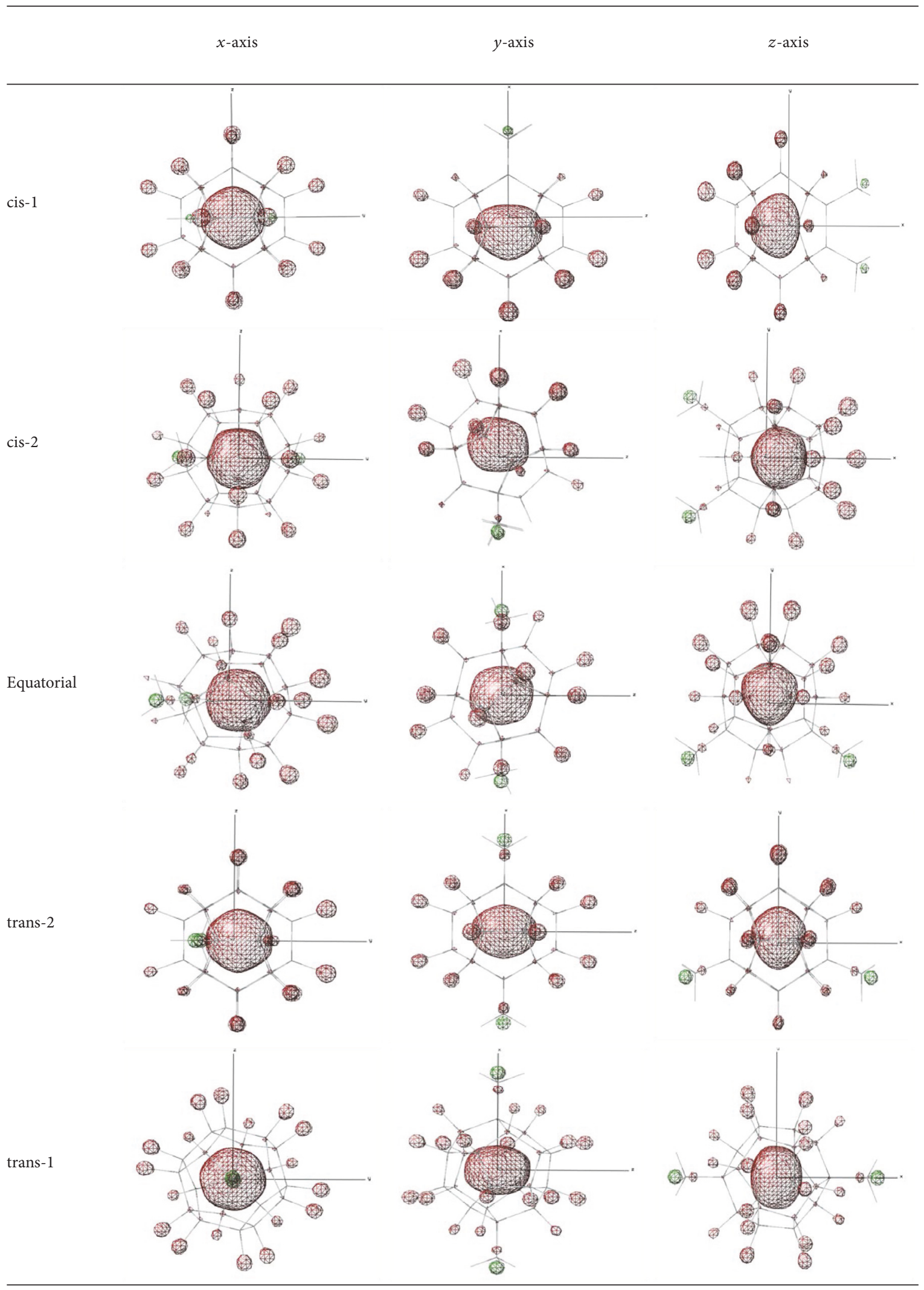

(b)

FIGURE 2: The (a) HOMOs and (b) LUMOs of the fully optimized geometries of the five $\mathrm{C}_{20} \mathrm{H}_{18}\left(\mathrm{CH}_{3}\right)_{2}$ derivatives using B3LYP/6-31G(d,p) calculations. Here $X-, Y$-, and $Z$-axis represent the frontier orbitals, looking from $x, y$, and $z$ direction, respectively. The HOMOs of $\mathrm{C}_{20} \mathrm{H}_{18}\left(\mathrm{CH}_{3}\right)_{2}$ derivatives (isovalue $\left.=0.05\right)$. trans-2 $(\mathrm{HOMO}:-7.08 \mathrm{eV}$ ) and the others (HOMO: -7.05$) ; \mathrm{C}_{20} \mathrm{H}_{20}(\mathrm{HOMO}:-7.09 \mathrm{eV})$. The LUMOs of $\mathrm{C}_{20} \mathrm{H}_{18}\left(\mathrm{CH}_{3}\right)_{2}$ derivatives (isovalue $=0.05$ ). Five dimethyl derivatives (LUMO: $0.98 \mathrm{eV}$ ); $\mathrm{C}_{20} \mathrm{H}_{20}(\mathrm{LUMO}: 0.90 \mathrm{eV}$ ). 


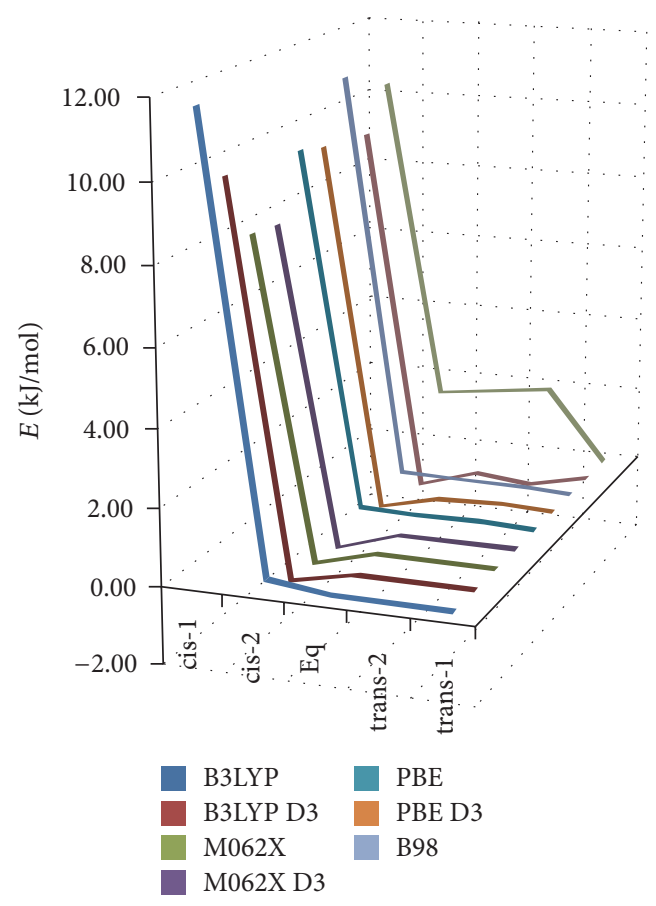

FIGURE 3: Trends in relative energies (unit: $\mathrm{kJ} / \mathrm{mol}$ ) for five isomers computed as single-point calculations at all different levels of DFT/ 6-31G(d, p)//B3LYP/6-31G(d, p) and MP2/def2-TZVPP//B3LYP/6$31 G(d, p)$.

were preparative-synthetic and suggest that 1,7-dimethyl derivative (equatorial, $\mathbf{C}_{2}$ ) would be synthesized in the near future.

\section{Conflicts of Interest}

The authors declare that there are no conflicts of interest regarding the publication of this paper.

\section{Acknowledgments}

This study was supported by Wonkwang University in 2015.

\section{References}

[1] S. Abe, S. Kawano, Y. Toida et al., "Electronic states of alkylradical-functionalized $\mathrm{C} 20$ fullerene using density functional theory," Japanese Journal of Applied Physics, vol. 55, no. 3, Article ID 03DD03, 2016.

[2] S. C. Wang and D. J. Tantillo, "Viability of dodecahedraneforming radical polycyclizations," Organic \& Biomolecular Chemistry, vol. 15, no. 9, pp. 1976-1979, 2017.

[3] R. Ghafouri and F. Ektefa, "Theoretical study on the mechanism of reactions of $\mathrm{CX} 3$ radicals (X $=\mathrm{H}, \mathrm{F}, \mathrm{Cl}$ and $\mathrm{Br}$ ) with $\mathrm{C} 20 \mathrm{H} 20$ and C20F20 fullerenes," Journal of Molecular Structure, vol. 1127, pp. 296-302, 2017.

[4] S. G. Semenov and M. V. Makarova, "A quantum chemical study of diethynyl derivatives of dodecahedrane and buckminsterfullerene in vacuum and in tetrahydrofuran," Optics and Spectroscopy, vol. 118, no. 1, pp. 46-49, 2015.
[5] L. A. Paquette, D. W. Balogh, R. Usha, D. Kountz, and G. G. Christoph, "Crystal and molecular structure of a pentagonal dodecahedrane," Science, vol. 211, no. 4482, pp. 575-576, 1981.

[6] L. A. Paquette and D. W. Balogh, "An expedient synthesis of 1,16dimethyldodecahedrane," Journal of the American Chemical Society, vol. 104, no. 3, pp. 774-783, 1982.

[7] G. G. Christoph, P. Engel, R. Usha, D. W. Balogh, and L. A. Paquette, "Comparative X-ray crystal structure analysis of $\mathrm{C} 2 \mathrm{v}$-dimethylmonosecododecahedrane and D3d-dimethyldodecahedrane. The remarkable consequences of a missing framework bond on molecular topology," Journal of the American Chemical Society, vol. 104, no. 3, pp. 784-791, 1982.

[8] L. A. Paquette, "Dodecahedrane-The chemical transliteration of Plato's universe (A Review)," Proceedings of the National Academy of Sciences of the United States of America, vol. 79, no. 14, pp. 4495-4500, 1982.

[9] L. A. Paquette, R. J. Ternansky, D. W. Balogh, and W. J. Taylor, "Total synthesis of a monosubstituted dodecahedrane. The methyl derivative," Journal of the American Chemical Society, vol. 105, no. 16, pp. 5441-5446, 1983.

[10] L. A. Paquette, R. J. Ternansky, D. W. Balogh, and G. Kentgen, "Total synthesis of dodecahedrane," Journal of the American Chemical Society, vol. 105, no. 16, pp. 5446-5450, 1983.

[11] H. Prinzbach and W.-D. Fessener, Organic Synthesis, Blackwell, Oxford, UK, 1987.

[12] M. Bertau, F. Wahl, A. Weiler et al., "From pagodanes to dodecahedranes - Search for a serviceable access to the parent (C20H20) hydrocarbon," Tetrahedron, vol. 53, no. 29, pp. 1002910040, 1997.

[13] L. A. Paquette, Y. Miyahara, and C. W. Doecke, "Preparatively useful dehydrogenative method for dodecahedrane synthesis," Journal of the American Chemical Society, vol. 108, no. 7, pp. $1716-1718,1986$.

[14] I. Santas, D. W. Balogh, C. W. Doecke, A. G. Marshall, and L. A. Paquette, "Gas-phase basicities of cubane, dodecahedrane, and methyl-and 1,16-dimethyldodecahedrane as measured by Fourier transform ion cyclotron resonance mass spectrometry," Journal of the American Chemical Society, vol. 108, no. 26, pp. 8183-8185, 1986.

[15] L. A. Paquette and Y. Miyahara, "Directed alkyl substitution of the dodecahedrane nucleus. The 1,4-dimethyl, 1,6-dimethyl, and 1,4,16-trimethyl derivatives. Indanododecahedrane by stepwise dehydrogenation of a benzylated seco derivative," The Journal of Organic Chemistry, vol. 52, no. 7, pp. 1265-1272, 1987.

[16] N. L. Allinger, H. J. Geise, W. Pyckhout, L. A. Paquette, and J. C. Gallucci, "Structures of norbornane and dodecahedrane by molecular mechanics calculations (MM3), X-ray crystallography, and electron diffraction," Journal of the American Chemical Society, vol. 111, no. 3, pp. 1106-1114, 1989.

[17] F. Wahl, J. Wörth, and H. Prinzbach, "The Pagodane Route to Dodecahedranes: An Improved Approach to the $\mathrm{C}_{20} \mathrm{H}_{20}$ Parent Framework; Partial and Total Functionalizations-Does $\mathrm{C}_{20}$ Fullerene Exist?" Angewandte Chemie International Edition, vol. 32, no. 12, pp. 1722-1726, 1993.

[18] J. M. Schulman and R. L. Disch, "Theoretical studies of dodecahedrane. 2. Dodecahedrane, inclusion compounds, and fluorine derivatives," Journal of the American Chemical Society, vol. 100, no. 18, pp. 5677-5681, 1978.

[19] D. Moran, F. Stahl, E. D. Jemmis, H. F. Schaefer III, and P. V. R. Schleyer, "Structures, stabilities, and ionization potentials of dodecahedrane endohedral complexes," Journal of Physical Chemistry A, vol. 106, no. 20, pp. 5144-5154, 2002. 
[20] Y. G. Hwang, S. Lee, and K. H. Lee, "DFT Study for Substitution Patterns of $\mathrm{C}_{20} \mathrm{H}_{18} \mathrm{X}_{2}$ Regioisomers (X = F, Cl, Br, or $\mathrm{OH}$ )," Bulletin of the Korean Chemical Society, vol. 33, no. 2, pp. 641646, 2012.

[21] A. D. Becke, "Density-functional thermochemistry. III. The role of exact exchange," The Journal of Chemical Physics, vol. 98, no. 7, p. 5648, 1993.

[22] C. Lee, W. Yang, and R. G. Parr, "Development of the ColleSalvetti correlation-energy formula into a functional of the electron density," Physical Review B, vol. 37, no. 2, pp. 785-789, 1988.

[23] P. J. Stephen, F. J. Devlin, C. F. Chablowski, and M. J. Frisch, "Ab Initio Calculation of Vibrational Absorption and Circular Dichroism Spectra Using Density Functional Force Fields," The Journal of Physical Chemistry, vol. 98, no. 45, pp. 11623-11627, 1994.

[24] R. H. Herteing and W. Koch, "On the parameterization of the local correlation functional. What is Becke-3-LYP?" Chemical Physics Letters, vol. 268, no. 5-6, pp. 345-351, 1997.

[25] W. J. Hehre, K. Ditchfield, and J. A. Pople, "Self-consistent molecular orbital methods. XII. Further extensions of gaussiantype basis sets for use in molecular orbital studies of organic molecules," The Journal of Chemical Physics, vol. 56, no. 5, pp. 2257-2261, 1972.

[26] M. J. Frisch, G. W. Trucks, H. B. Schlegel et al., A Gaussian 03, B.04, Gaussian, Inc., Pittsburgh, Pa, USA, 2003.

[27] M. J. Frisch, G. W. Trucks, H. B. Schlegel et al., Gaussian 09W, Rev: D01, Gaussian, Inc., Pittsburgh, Pa, USA, 2009.

[28] T. Clark and R. Koch, The Chemist's Electronic Book of Orbitals, Springer Berlin Heidelberg, Berlin, Germany, 1999.

[29] Y. Zhao and D. G. Truhlar, "The M06 suite of density functionals for main group thermochemistry, thermochemical kinetics, noncovalent interactions, excited states, and transition elements: two new functionals and systematic testing of four M06-class functionals and 12 other functionals," Theoretical Chemistry Accounts, vol. 120, no. 1, pp. 215-241, 2008.

[30] J. P. Perdew, K. Burke, and M. Ernzerhof, "Generalized gradient approximation made simple [Phys. Rev. Lett. 77, 3865 (1996)]," Physical Review Letters, vol. 78, no. 7, p. 1396, 1997.

[31] H. L. Schmider and A. D. Becke, "Optimized density functionals from the extended G2 test set," The Journal of Chemical Physics, vol. 108, no. 23, p. 9624, 1998.

[32] A. D. Beck, "Density-functional thermochemistry. V. Systematic optimization of exchange-correlation functionals," The Journal of Chemical Physics, vol. 107, no. 20, p. 8554, 1997.

[33] S. Grimme, S. Ehrlich, and L. Goerigk, "Effect of the damping function in dispersion corrected density functional theory," Journal of Computational Chemistry, vol. 32, no. 7, pp. 14561465, 2011.

[34] M. Head-Gordon, J. A. Pople, and M. J. Frisch, "MP2 energy evaluation by direct methods," Chemical Physics Letters, vol. 153, no. 6, pp. 503-506, 1988.

[35] F. Weigend and R. Ahlrichs, "Balanced basis sets of split valence, triple zeta valence and quadruple zeta valence quality for $\mathrm{H}$ to Rn: design and assessment of accuracy," Physical Chemistry Chemical Physics, vol. 7, no. 18, pp. 3297-3305, 2005.

[36] B. S. Hudson, D. G. Allis, S. F. Parker, A. J. Ramirez-Cuesta, H. Herman, and H. Prinzbach, "Infrared, Raman, and inelastic neutron scattering spectra of dodecahedrane: An I h molecule in T h site symmetry," Journal of Physical Chemistry A, vol. 109, no. 15, pp. 3418-3424, 2005.
[37] F. Wahl, A. Weiler, P. Landenberger et al., "Towards perfunctionalized dodecahedranes-en route to C20 fullerene," Chemistry - A European Journal, vol. 12, no. 24, pp. 6255-6267, 2006. 

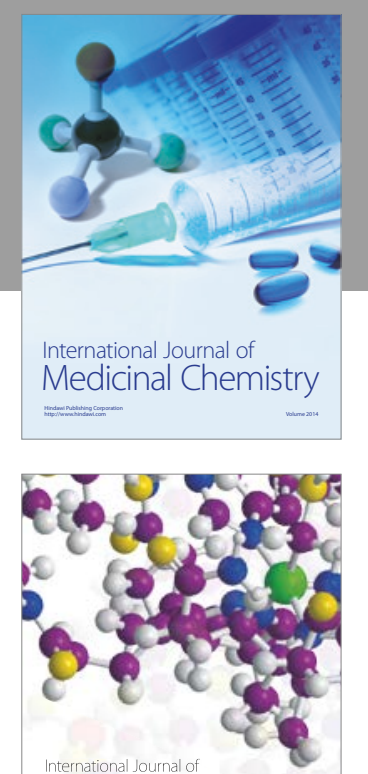

Carbohydrate Chemistry

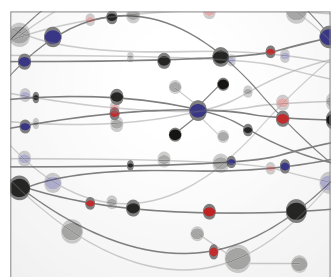

The Scientific World Journal
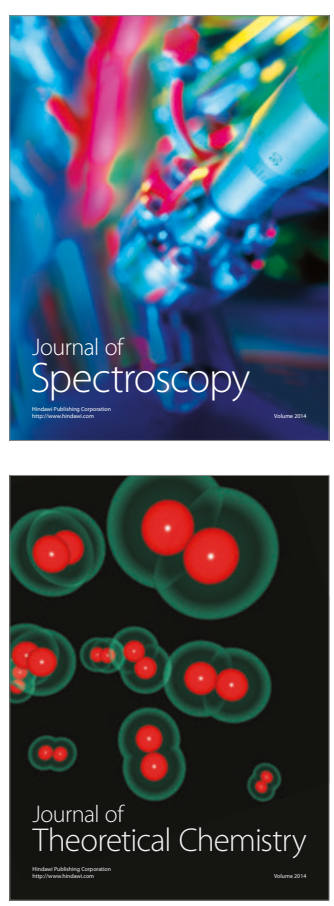
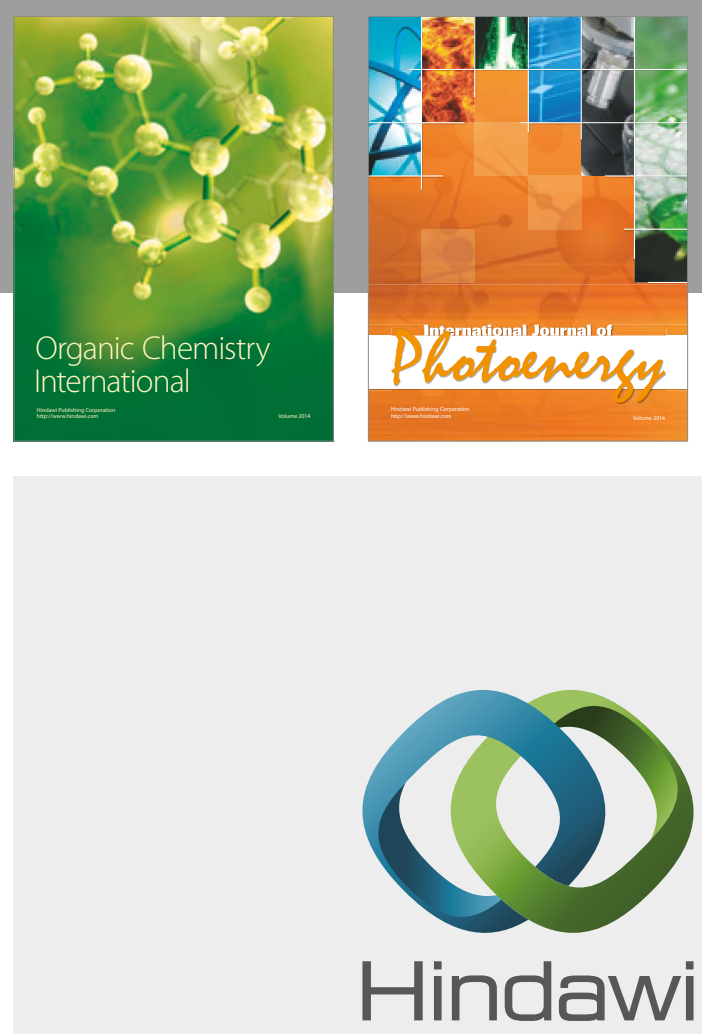

Submit your manuscripts at

https://www.hindawi.com

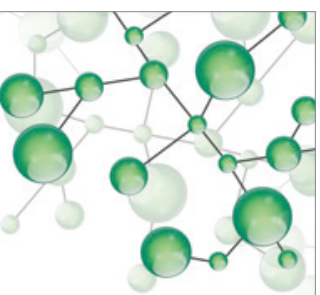

International Journal of

Inorganic Chemistry

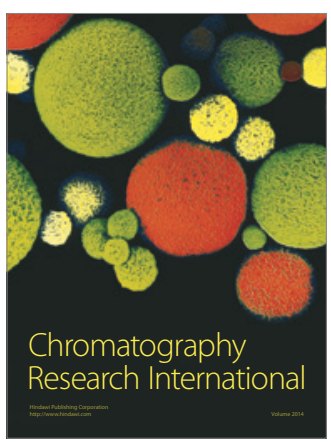

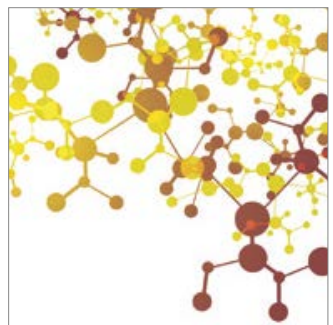

Applied Chemistry
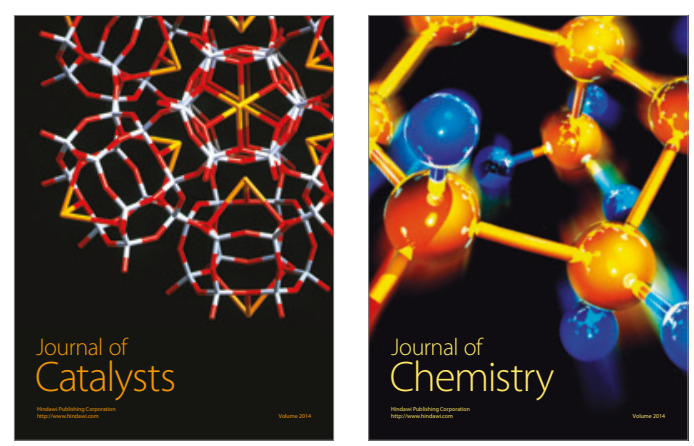
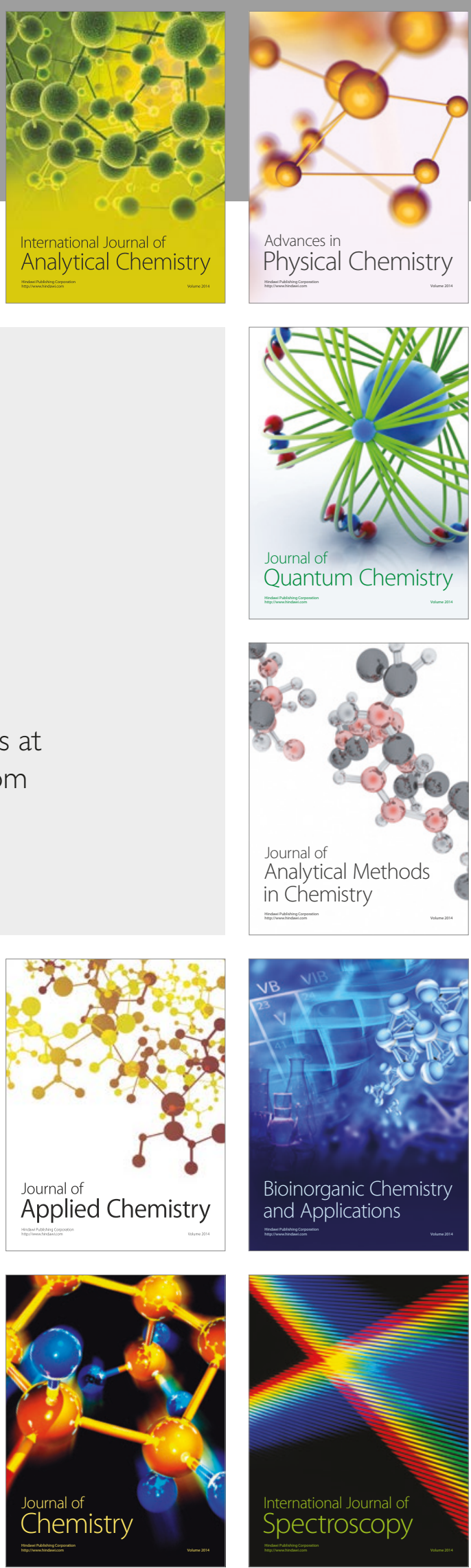